\title{
O cidadão e o legislador na ética e política de Aristóteles.
}

Martin Prado Sander Smit

\section{Resumo:}

O cidadão e o legislador são conceitos de grande importância tanto na Ética a Nicômacos quanto na Política. É dos dois que depende a autossuficiência da cidade e a felicidade de seus habitantes, ou seja, a realização da finalidade da ciência política e da ética. A partir disso, este trabalho se propõe a elaborar a relação entre essas duas figuras, considerando o que é necessário para que alguém seja um bom cidadão e, no caso do legislador, o que o torna capaz de instituir uma boa constituição, e aquilo em que ela consiste. Nessas questões, delineiase mais claramente a relação entre os dois: o bom cidadão depende de boas leis (em sua formação e em sua convivência com outros cidadãos), elaboradas por bons legisladores, assim como o trabalho desses legisladores só alcança de fato sua finalidade se as leis são respeitadas e promovidas por cidadãos virtuosos.

Palavras-chave: Aristóteles, Ética, Filosofia Política, Gidadão, Legislador. 
Não existe uma fronteira entre questões éticas e políticas no pensamento aristotélico. De maneira geral, conforme explica Morrall: "não existe qualquer texto escrito que apoie a crença de que Aristóteles reconhecesse uma ciência ética separada. Para o filósofo, o comportamento ético individual é uma subdivisão do que chama 'ciência política', uma exploração intelectual geral dos campos inseparáveis da vida individual e da vida comunitária, que juntos compõem a unidade da polis". ' O papel que tanto um quanto outro desempenha na vida dos homens não está, portanto, isolado na ética ou na política, mas é comum a essas duas esferas da vida coletiva.

Considerando essa relação intrínseca entre a finalidade de um único individuo e a de toda a cidade, esta comunicação se propõe a traçar alguns pontos da relação entre os conceitos de cidadão e de legislador na filosofia prática de Aristóteles. Partindo da consideração sobre o que é necessário para que alguém seja um bom cidadão e, no caso do legislador, sobre o que o torna capaz de instituir uma boa constituição e no que ela consiste, podemos conceber uma relação mais clara entre os dois.

As funções e a importância do trabalho tanto de um quanto de outro podem ser delineadas a partir de uma definição da própria cidade, como acontece no livro III da Política, em que, no final do primeiro capítulo, Aristóteles define a cidade como "o conjunto de cidadãos suficiente para viver em autarquia". ${ }^{2}$ Esse conjunto de partes constitutivas da cidade, o grupo dos cidadãos, é aquele grupo de pessoas às quais cabe manter a cidade apta para a autossuficiência e para o cultivo da maior felicidade possível de seus habitantes, ou seja, é o grupo a quem cabe realizar o fim último da polis. Uma definição da cidade passa, portanto, por uma definição de cidadão. Para defini-lo, Aristóteles afirma que:

"não há melhor critério (...), em sentido estrito, do que entender a cidadania como capacidade de participar na administração da justiça e no governo". ${ }^{3}$

O cidadão é aquele habitante da cidade que pode exercer uma função no governo, um cargo de juiz ou de membro das assembleias. Mesmo no caso dos cargos de exercício alternados, um cidadão que deixe um cargo não deixa de ser cidadão; o que o caracteriza enquanto tal é a igualdade que ele tem em relação aos outros, que, mesmo que efetivamente não exerçam aquele cargo, podem vir a exercê-lo, tê-lo exercido ou mesmo exercer outro cargo no governo ou nas assembleias e tribunais, que todos têm a capacidade de executar. É a eles que

I Morrall, J.B. Aristóteles, pág. 49

$2 \mathrm{I} 275 \mathrm{~b} 20$

3 ARISTÓTELES, Política, III, i, I275 20-27 
cabe a direção da cidade e são eles que, uma vez atribuídas suas funções, nos permitem dizer que a cidade "praticou este ou aquele ato", 4 visto que um ato praticado pela cidade é um ato praticado por aqueles a quem são atribuídos os poderes que a cidade tem sobre cada um de seus habitantes.

Aqui é preciso lembrar que é do regime (politeia) que depende essa organização de poderes e atribuições, e, por isso, conforme observa Wolff, "o conteúdo real do conceito de cidadão depende do tipo de regime", ${ }^{5}$ ou seja, o que realmente implica que determinado habitante seja cidadão é o regime sob o qual se encontra a cidade. Considerando que os regimes que determinam e organizam as atribuições dos poderes são diferentes nas diferentes cidades, do mesmo modo serão diferentes os critérios da cidadania. Por isso, para conhecer o que é um cidadão e como alguém pode ser chamado de cidadão, é preciso considerar aquilo em que consiste a cidadania nas várias formas de regime das várias cidades. O titulo de cidadão é o que dá a um habitante o direito da participação política e é dessa atividade que dependem, aliados a fatores circunstanciais, os fins da política: a autonomia da cidade e a maior felicidade possível entre os que nela vivem.

Este último é objetivo máximo da ciência política, pois é essa a ciência que, conforme Burnet, "produz felicidade em uma Gidade (a state), e a felicidade é o maior dos bens práticos (practical goods), a única coisa que escolhemos por ser um fim em si mesma (for its own sake), e não por qualquer fim que esteja além dele", 6 Por isso a política é a ciência "mais imperativa e mais predominante sobre tudo"; além de utilizar as ciências restantes, ainda legisla sobre o que devemos ou não fazer. ${ }^{7}$

A política, assim como as outras ciências, visa a um gênero determinado e, portanto, para examinar o que é adequado aos regimes políticos, não é possível levar em consideração apenas um aspecto parcial de seu objeto de estudo, mas deve-se considerar o gênero como um todo. No início do livro IV da Política, Aristóteles afirma que o bom legislador é justamente aquele que não negligencia nenhum dos aspectos que o estudo desse gênero requisita, listando-os ainda no primeiro capítulo.

Um bom legislador não deve negligenciar a constituição do regime ideal, mas o exame desse objeto em seu estado ideal não esgota a ciência política. Para ele, não basta o estudo do regime ideal sobre condições ideais. É preciso ainda saber qual é o melhor regime para uma cidade que vive em circunstâncias

4 op. cit. III, i, I274 $34^{\mathrm{I}}-32$

5 WOLFF, Aristóteles e a Política, pág. II7

6 BURNET, Aristotle on Education, pág. 5

7 Gf. ARISTÓTELES, Ética a Nicômacos, I, ii, Io94 ${ }^{\text {a }}$ 
geográficas e humanas diferentes das ideais, além de saber qual o melhor regime não só para determinada cidade, mas também para a maioria das cidades, consideradas "como se fossem uma só". 8

Além disso, como coloca Aristóteles, da mesma forma que um mestre de ginástica tem que considerar que não são todos os homens que estão aptos a se tornarem campeões das competições, pois nem todos aqueles que se exercitam o fazem para atingir a melhor condição física possível, o legislador não deve negligenciar uma cidade que, mesmo não desejando ou não estando apta a existir sob a melhor constituição, deseja ao menos viver em seu regime da melhor maneira possível.

Para um cientista político, não basta examinar o regime perfeito nem conhecer qual o melhor regime dentro de circunstâncias específicas, pois ainda é preciso que não seja negligenciado "um terceiro regime que se estabelece segundo um pressuposto, uma vez que essa ciência pode também examinar qual o princípio a partir do qual um regime se formou, e de que forma o poderemos conservar o máximo de tempo possível”. Assim, não basta que o legislador e o político saibam apenas criar ou escolher um regime (nem o melhor, nem o mais adequado, nem o que mais serve à maioria das cidades), pois o político deve ainda "ser capaz de auxiliar os regimes já estabelecidos", organizados a partir de um princípio que o legislador deve conhecer e respeitar durante sua atuação política. ${ }^{9}$

Com isso, o problema de como implantar o regime perfeito dá lugar ao problema prático que o conhecimento político precisa compreender. O que o legislador deve conhecer, ao contrário de um cientista especulativo, é antes a possibilidade prática de execução de um regime do que sua correspondência à organização ideal de uma cidade. Conforme Aristóteles, "o que verdadeiramente interessa, pelo contrário, é introduzir uma ordenação política cujas disposições persuadam facilmente os cidadãos e facilmente sejam adotadas; pois não é de modo algum menos trabalhoso o ato de aprender melhor do que o ato de

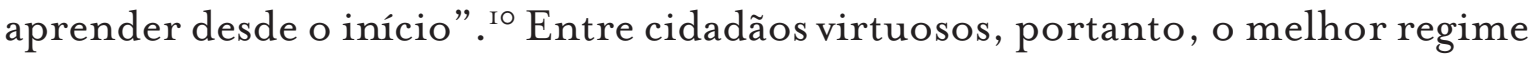
possível é persuasivo, pois eles realmente sabem o que é o melhor em sentido absoluto. Mas os homens, em sua maioria, necessitam de outros elementos de compulsão, como a possibilidade de ganhos e o medo de punições. Cabe ao legislador levar essas circunstâncias em consideração, pois só assim será possível formular um regime específico que funcione da melhor maneira possível em uma cidade específica.

8 Para todo o parágrafo Gf. ARISTÓTELES, Política, IV,I288

9 Para todo o parágrafo Cf. ARISTÓTELES, Política, IV, i, I288 20 - I289 a 5

Io ARISTÓTELES, Política, IV, i, I289 a I-4 
Mas não basta que a cidade tenha uma boa legislação para que ela seja autossuficiente e seus habitantes tenham uma boa vida. A cidade é a comunidade de cidadãos, ela existe no mundo real como o lugar da vida em comum, onde os homens vivem juntos e o que um faz ou deixa de fazer influencia a vida dos outros que vivem com ele. É papel das leis organizar as condutas, validando aquelas que convêm à cidade e proibindo aquelas que desviam a cidade de seu fim. Por isso, nesse ponto, a investigação política se torna uma investigação ética: cabe agora investigar como deve ser a conduta de um cidadão, e quais atos devem ser elogiados ou censurados, bem como qual é a melhor maneira de formar os cidadãos, de modo que se tornem homens bons.

Considerando que isso é necessário para tornar a cidade boa, ou seja, que isso é necessário para que o fim do legislador seja atingido, segue que o legislador deve se preocupar com os cidadãos e com a maneira como eles podem vir a praticar boas ações e cultivar bons hábitos. É nesse sentido que Burnet afirma que é papel da legislação organizar as leis que tratam da educação, a fim de que a cidade possa "produzir o tipo de cidadão que o legislador precisa para a constituição que ele deve preservar". "I Partindo do que os habitantes são desde o nascimento, cabe ao legislador conceber sua formação de modo que eles se tornem bons cidadãos, capazes de, em sua fase adulta, tornarem-se bons políticos e bons legisladores, atingindo com excelência a finalidade a que eles visam na condição de cidadãos.

Por isso, a educação, este processo que desenvolve no homem aquilo que ele tinha em potência, é de máxima importância para a política, e não deve ser negligenciada pelo legislador. É da educação que depende o equilíbrio da cidade, pois é dela que dependem os homens para se tornarem governantes equilibrados (spoudaioi). É formando esses homens para uma vida equilibrada e virtuosa que se garante o equilíbrio de seu trabalho como governantes da cidade e, por isso, a investigação política deve considerar o problema da educação e de que maneira a cidade deve se servir dela para promover sua felicidade e autossuficiência.

Cumprir essa tarefa é a finalidade que o legislador deve realizar para ser um bom legislador, ou seja, é a finalidade suprema da ciência política, que é "infundir certo caráter nos cidadãos - [...] torná-los bons e capazes de praticar boas ações". ${ }^{12}$ O legislador consegue realizar esse fim, para o qual os homens têm que estar aptos por natureza, educando os homens por intermédio dos hábitos e da instrução, com o que ele pode moldar aquilo que não foi determinado desde

II BURNET, Aristotle on Education, pág. 5 “... to produce the type of citizens which the statesman requires for the constitution it is his business to preserve..."

I2 ARISTÓTELES, Ética a Nicômacos, I, ix, I022b 
o nascimento (como as características naturais de certos povos) e pode por isso ser modificado. ${ }^{13}$

A formação dos hábitos e a instrução remetem, cada uma a seu modo, ao desenvolvimento de um tipo específico de excelência do homem. Quando trata da excelência humana, Aristóteles deixa claro que procura a excelência da alma, que é aquilo que o homem tem de próprio. ${ }^{I 4}$ A excelência do homem é a excelência da atividade de sua alma, e seus dois tipos de excelência correspondem à excelência da atividade de duas partes diferentes da alma: a excelência intelectual e a excelência moral. É para agir sobre essas diferentes partes que a ciência política deve estudar as partes da alma.

Por isso o estudo dessa questão não deve ser empreendido com o puro intuito de compreender; conforme Aristóteles, aquele que deseja se tornar um bom governante e legislador "deve estudá-la tendo em vista estes objetivos [tornar os homens bons], e apenas o suficiente em face das questões que estamos discutindo". ${ }^{15}$

Para assinalar a diferença entre essas duas partes da alma, ele traça a diferença pela qual cada uma delas se relaciona com a razão. Aquelas partes que não se relacionam com a razão (como as funções da alma vegetativa) não participam da virtude que é especificamente a virtude humana. Já os elementos que participam da razão "no sentido próprio e em si", ${ }^{16}$ são aqueles aos quais correspondem formas excelentes como a sabedoria, a inteligência e o discernimento: formas da excelência intelectual, que são adquiridas pela instrução. ${ }^{17}$

Mas há também outro elemento na alma, cuja atividade excelente corresponde à excelência moral. Esse elemento é irracional, mas participa da razão na medida em que pode ser persuadido por ela. Conforme escreve Aristóteles, "o fato de advertirmos alguém, e de reprovarmos e exortarmos de modo geral indica que a razão pode de certo modo persuadir o elemento irracional". ${ }^{18}$ Assim, para um homem temperante, esse elemento sempre obedece à razão, no sentido em que essas duas partes da alma funcionam juntas e apontam para a mesma direção; entretanto, nos homens incontinentes, o elemento irracional não obedece à razão, seus impulsos atuam em direções opostas assim como um membro paralisado se move para um lado quando pretendemos movê-lo para outro. ${ }^{19}$

I3 Cf. idem, Política, VII, xiii, I332b

I4 Gf. idem, Ética a Nicômacos, I, xiii, IIO2b

I5 Op. cit. I, xiii, IIO2a

I6 Op. cit. I, xiii, IIO3a

I7 Op. cit. II, i, IIO3a

I8 Op. cit. I, xiii, IIO2b

I9 Op. cit. I, xiii, IIO2b - IIO3a 
Podemos assim dizer que o fato de este elemento obedecer à razão é um sinal de sua excelência, pois os hábitos excelentes são aqueles que a razão escolheria. A inclinação para praticar esses atos, para agir de acordo com a razão, é o que nos é favorecido quando temos bons hábitos.

Os hábitos devem promover "alguma afinidade com a excelência moral, amando o que é nobilitante e detestando o que é aviltante", ${ }^{20}$ pois o prazer e o sofrimento acompanham "toda ação e toda emoção" ${ }^{21}$ e, por isso, têm uma grande importância para a ética e a política. De fato, já no Livro II da Ética a Nicômacos, Aristóteles destaca essa importância ao afirmar que "toda a preocupação, tanto da ciência moral quanto da ciência política, é com o prazer e o sofrimento, porquanto o homem que os usa bem é bom, e o que os usa mal é mau". ${ }^{22}$ Mas o que Aristóteles pretende significar como uma boa ou má utilização do prazer? Além disso, quais as decorrências dessa preocupação na ciência moral e na ciência política especificamente?

Seguindo essa ideia ainda no livro II, Aristóteles afirma que a causa dos homens se tornarem maus é o prazer e o sofrimento, pois é "perseguindo e evitando os prazeres e sofrimentos que não devem, ou quando não devem, ou como não devem”, que os homens cultivam as disposições da alma que os tornam maus. Esse prazer equivocado é que nos move a praticar más ações, e é o prazer que relacionamos com essas más atividades que nos estimula a praticá-las.

É nesse sentido que Aristóteles diz que os castigos são infligidos como sofrimentos. ${ }^{23}$ Devemos considerar que tanto a excelência ou a deficiência moral quanto o prazer e o sofrimento se relacionam com as emoções e as ações. ${ }^{24}$ Logo, quando se aplicam punições com o intuito de reprimir as más ações, ${ }^{25}$ os castigos funcionam como "uma espécie de tratamento médico" ${ }^{26}$ que, operando por meio de contrários, infligem um sofrimento para uma ação indevida e, portanto, para um prazer indevido. Se a ação fosse acompanhada por um prazer verdadeiro, seu agente não sofreria castigo ou punição, pois estaria praticando uma ação boa, o que deve ser encorajado pelo legislador. Habituar as pessoas a praticar o bem é seu objetivo, e ele terá criado uma boa constituição se colocar esse objetivo corretamente em prática; ${ }^{27}$ para isso, o legislador deve considerar

20 ibidem

2 I Op. cit. II, iii, IIO5

22 ibidem

23 Cf. ibidem

24 Cf. EN, II, 3, IIO4b

25 Conforme indica Aristóteles em IIO4a

26 Op. cit. II, iii, IIO4b

27 Cf. Op. cit. II, iii, IIO3b 
que "para o nosso bem ou para o nosso mal o fato de nos deleitarmos ou sofrermos tem uma influência nada pequena em nossas ações". ${ }^{28}$

Mas qual o critério pelo qual podemos chamar um prazer de verdadeiramente bom? E qual a utilidade do conhecimento desses prazeres para a ciência moral e a ciência política? No livro VII, Aristóteles retoma o problema do prazer, discutindo se o prazer é um bem, e explica que "aquilo que é bom pode ser bom em duas acepções (uma coisa pode ser irrestritamente boa, e outra pode ser boa para uma determinada pessoa)" ${ }^{29}$.

Assim, da mesma forma que determinadas atividades, determinados prazeres são irrestritos, enquanto outros o são para algumas pessoas e em algumas situações. Por isso, o estudo da natureza do prazer é fundamental para o filósofo político, que, conforme Aristóteles, "é o arquiteto dos fins com vistas aos quais chamamos certas coisas de más e outras de boas irrestritamente". ${ }^{30}$ Se a finalidade da moral e da política (a felicidade de um homem e de todos os homens da cidade) pressupõe o prazer, ${ }^{3 \mathrm{I}}$ é fundamental que o legislador o tenha em mente para ser bem-sucedido em sua intenção.

Mas em que consiste esse verdadeiro prazer e como ele acompanha as atividades do homem? No livro X, Aristóteles diz que esse prazer não é um movimento (que só é completo em sua totalidade ou em seu momento final) nem um desejo (o prazer é mais inerente ao ato do que os desejos), mas um "todo perfeito", contínuo, que surge como uma coroação de uma atividade excelente; esse prazer não é a excelência da respectiva disposição moral do agente, mas uma "perfeição cumulativa" (que Aristóteles compara ao "viço da juventude" ${ }^{2}$ ).

O prazer é, portanto, bom ou mau em virtude da atividade que o acompanha, ou seja, "os prazeres são inerentes às atividades" 33 e os melhores prazeres são aqueles que decorrem das melhores atividades. Mas uma pessoa corrompida não tem prazer com o que é virtuoso ${ }^{34}$ e é por isso que a "verdadeira educação" é aquela que ensina as pessoas a sentirem prazer com as coisas certas. É esse prazer - que, no início, provém do elogio recebido por certas formas de agir - que ajudará a formar hábitos virtuosos, pois é natural que se escolha o que é prazeroso. Por isso toda a preocupação, tanto da ciência moral quanto da ciência política, é com o prazer e com o sofrimento.

28 Cf. Op. cit. II, iii,IIO5a

29 Op. cit. VII, xii, II $52^{\mathrm{b}}$

30 Op. cit. VII, xi, $\operatorname{II} 52^{a}$

3I ibidem

32 Gf. Op. Cit. X, iv

33 Op. cit. X, v, II $76^{\mathrm{a}}$

34 Cf. ibidem 
Assim, um homem que tem uma boa formação dos hábitos (que é uma boa formação moral) se sentirá inclinado a respeitar a lei e praticar atos justos, que são aqueles atos que colaboram para a felicidade e autossuficiência da cidade; é só um homem virtuoso que pode decidir, pelos motivos certos, a prática de atos realmente justos.

No livro V, Aristóteles trata da justiça, distinguindo-a em um sentido amplo e um restrito. Em sentido restrito, a justiça e a injustiça são apenas uma parte daquilo que são em sentido amplo. Um ato injusto nesse sentido não pode ser imputado à deficiência moral como um todo (como seria com a injustiça em sentido amplo), mas somente a uma de suas formas, que Aristóteles chama de iniquidade. ${ }^{35}$

Já o sentido amplo (do qual o restrito é apenas uma parte) é aquele pelo qual Aristóteles afirma que "chamamos justos os atos que tendem a produzir a felicidade e preservar os elementos que a compõem [...] para a comunidade política" ${ }^{36}$ É a justiça no sentido da legalidade, aquela que se relaciona com a obediência às leis: são as leis que tornam os homens corajosos (como as leis que nos impedem de desertar do posto), moderados (como aquelas que não permitem que cometamos adultério), amáveis (quando as leis não nos permitem que agridamos os outros) e assim por diante com cada forma de disposição excelente. ${ }^{37}$

É por meio dessa justiça que podemos exercer a virtude não só em relação a nós mesmos como também em relação aos outros. ${ }^{38}$ Mas a justiça pressupõe uma igualdade entre aquele que age e aquele que recebe a ação; ambos (ao contrário de um senhor e seus escravos, ou um pai e seus filhos pequenos) ocupam a mesma posição em relação à lei. Por isso só entre pessoas "cujas relações mútuas são definidas pela lei" 39 as ações podem ser chamadas de justas, e é a própria observância da lei que as torna tais, ou seja, só há justiça nas cidades onde o legislador instituiu um estado de direito.

Assim, no início do livro $\mathrm{V}$ da Ética a Nicômacos, parece que o critério das ações justas depende apenas do legislador; é ele quem decide o que é justo ou injusto; para os cidadãos, a justiça e a injustiça consistem apenas em estar ou não de acordo com o critério estabelecido pela lei.

Mais adiante, Aristóteles coloca um problema nessa relação. De acordo com ele, "cada uma das regras de justiça e das regras legais se relaciona com as ações da mesma forma que o universal se relaciona com os casos particulares, pois as ações praticadas são muitas, enquanto cada regra ou lei é uma, já que é

35 Cf. Op. cit. V, i, II29

36 Op. cit. V, i, $1129^{\mathrm{b}}$

37 Cf. Op. cit. V, i, II $29^{\mathrm{b}}-\mathrm{II} 3 \mathrm{O}^{\mathrm{a}}$

38 Cf. Op. cit. V, ii, II30

39 Cf. Op. cit. V, vi, II $34^{\mathrm{b}}$ 
universal". ${ }^{\circ}$ Sobre esse ponto, Aubenque aponta que, por visarem ao geral, as leis (assim como a ciência) são proposições gerais que não podem abranger todas as variações do particular. Essa generalidade da lei é a própria razão de sua falibilidade, pois uma lei, que é por essência geral, não pode dar conta da multiplicidade das circunstâncias em que as ações são praticadas. ${ }^{4 \mathrm{I}} \mathrm{A}$ impossibilidade de uma lei infalível não depende da habilidade do legislador, mas é um "obstáculo ontológico", ${ }^{42}$ implícito em sua própria atividade: as leis, que são gerais, são insuficientes para garantir a formação de bons cidadãos.

A superação desse problema só é possível pela equidade, pois o equitativo, que "é em si mesmo justo", pode corrigir a lei, aplicando-a em determinada situação particular de maneira apropriada. Assim o equânime é "por sua natureza, uma correção da lei onde essa é omissa devido à sua generalidade". ${ }^{43}$

Aos cidadãos não cabe somente seguir irrestritamente as leis, pois eles agem em circunstâncias particulares e têm de observar leis gerais. O critério dos atos justos, antes de estar nas formulações das leis escritas, está na capacidade de julgar se uma lei deve ser aplicada em determinada circunstância, de aplicar a lei correta na situação correta e da maneira correta. Por isso, a equidade funciona como um "corretivo da justiça legal". A equidade dos homens virtuosos, que conseguem ver qual ação é justa em cada situação particular, "é um corretivo da falibilidade da lei". ${ }^{44}$

Podemos chamar então de justas em sentido amplo não só as ações de acordo com a lei, mas também (e principalmente) as ações dos homens realmente justos, que observam a lei e, se preciso, corrigem-na com a equidade. São esses, mais especificamente, "os atos que tendem a produzir a felicidade e preservar os elementos que a compõem [...] para a comunidade política”, ${ }^{45}$ e, portanto, a justiça em sua forma mais completa não está nem na letra da lei (formulada pelo legislador) nem em sua simples observância, mas no homem bom que consegue trazer para o particular as regras gerais do primeiro, praticando atos realmente justos para si e para os outros que vivem com ele.

Por fim, ao longo dessas considerações, podemos ter uma visão mais aprofundada da importância do legislador e do cidadão no quadro da vida política concebido por Aristóteles. Para que sua finalidade seja atingida, é preciso que tanto os cidadãos quanto os legisladores sejam virtuosos, ou seja, ambos devem agir bem, de acordo com decisões acertadas, dentro da parte que cabe a cada uma dessas duas figuras no quadro da cidade. Conforme ele observa:

40 Cf. Op. cit. V, vi, II $35^{\mathrm{a}}$

4I Cf. AUBENQUE, A Prudência em Aristóteles, pág. 75

42 ibidem

43 ARISTÓTELES, Ética a Nicômacos, V, x, II $37^{\mathrm{b}}$

44 Cf. AUBENQUE, A Prudência em Aristóteles, pág. 76

45 ARISTÓTELES, Ética a Nicômacos, V, i, II29 
"No caso da sabedoria relacionada com os assuntos da cidade, a forma de discernimento que desempenha o papel dominante é a ciência legislativa, enquanto a que se relaciona com os casos particulares é conhecida pela denominação genérica de ciência política; esta é pertinente à ação e à deliberação, pois um decreto é algo a ser cumprido sob a forma de um ato individual". ${ }^{4}{ }^{6}$

Com isso podemos compreender a complementaridade do cidadão e do legislador no quadro da cidade. Por um lado, a cidade é um todo, anterior a todos os cidadãos (assim como o todo é anterior às partes). ${ }^{47} \mathrm{E}$ a ordem instituída dos poderes e benefícios da cidade, que é organizada pelas leis instituídas pelo legislador. Essa organização deve estar de acordo com a finalidade para a qual a cidade se dirige, pois de outro modo esse regime não sobreviverá e a cidade não será autônoma.

É papel do legislador organizar essas leis da melhor forma possível, de modo que a cidade esteja orientada para a sua finalidade e, mesmo que não atinja realmente o grau ideal de perfeição, se aproxime dele o máximo possível. Além disso, quando o legislador se encontra em uma cidade que já está direcionada para um fim (um fim que não tenha sido estabelecido por ele, ou mesmo um fim que ele não escolheria), é seu papel organizar as leis de forma a preservar esse regime, ou seja, fazer com que ele seja seguido e respeitado pela população da cidade o máximo permitido pelas circunstâncias.

Mas a cidade não é apenas um esquema legal e racional de organização dos poderes, é algo que acontece na realidade prática. A política, enquanto ciência prática, não tem apenas o papel de conhecer a melhor forma de tratar dessas questões, mas, sobretudo, o de resolvê-las, ou seja, de fazer com que os homens que vivem na cidade vivam efetivamente uma boa vida. Nesse ponto, é aos cidadãos que cabe cumprir um papel. De fato, são eles que respeitarão as leis, cuidarão da manutenção dos hábitos, praticarão bons atos e corrigirão as situações em que a lei não foi respeitada, trazendo aquela finalidade pretendida pela legislação para a realidade comum dos habitantes da cidade.

O problema que Aubenque aponta como "obstáculo" da atividade do legislador (o fato de uma lei universal não dar conta da multiplicidade de situações do particular) é justamente o que exige o desenvolvimento da virtude política (essa forma particular de discernimento a que Aristóteles se refere) dos cidadãos em geral, que é a virtude exercida nas situações particulares (e não a virtude em fixar leis gerais), completando assim o campo do qual a legislação depende (pois se legisla sobre atos que podem ou não ser exercidos), permitindo a realização particular de um princípio geral.

46 ARISTÓTELES, Ética a Nicômacos, VI, viii, II4I I

47 Cf. idem, Política, I, passim 
Quando os cidadãos vivem juntos sob as leis é que podemos dizer que a forma pensada pela legislação existe em condições reais, materializada pelos cidadãos. Para atingir sua finalidade, a ciência política deve contar, portanto, tanto com a excelência dos legisladores quanto com a excelência dos cidadãos. Aquilo que falta aos homens para torná-los excelentes (a boa educação e a vida na cidade, sob a organização das leis) é proporcionado pelo legislador; aquilo que falta ao legislador (a conclusão do caminho que leva da lei, que é uma, às situações onde uma ação é justa, que são muitas) é realizado pelos cidadãos, e assim a cidade pode efetivamente proporcionar uma vida boa para aqueles que nela vivem.

\section{Referências bibliográficas:}

Aristóteles - Ética a Nicômacos. Trad. de Mário da Gama Kury 2 edição Brasília, ed. Universidade de Brasília, I992.

Política. Trad. de Mário da Gama Kury, $3^{\text {a }}$ edição Brasília, ed. Universidade de Brasília, I997.

Política. Trad. e notas António Campelo Amaral e Carlos de Carvalho Gomes, Lisboa, ed. Veja, I998.

Aubenque, Pierre - A Prudência em Aristóteles, trad. de Marisa Lopes - São Paulo, Discurso Editorial, 2003.

Burnet, J. - Aristotle on Education, Londres, Cambridge University Press, I973

Morrall, J. B.-Aristóteles. Trad. de Sérgio Duarte, $2^{\mathrm{a}}$ edição, Brasília, Ed. Universidade de, I985

Wolff, Francis - Aristóteles e a Política, trad. de Thereza Christina Ferreira Stummer e Lygia Araujo Watanabe, São Paulo, Discurso Editorial, I999.

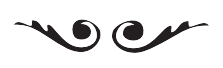

Martin Prado Sander Smit é graduando em Filosofia pela USP.

E-mail: martin_smit@hotmail.com 